\title{
THE IMAGINARY LACAN SEBAGAI INSPIRASI PENCIPTAAN SKENARIO FILM PENDEK SEKUEL KEDUA FILM KOPER GENDIS MENCARI JAWAB MENAKAR TANYA
}

\author{
Philipus Nugroho Hari Wibowo, Surya Farid Sathotho \\ Institut Seni Indonesia Yogyakarta \\ philipus.bowo@isi.ac.id
}

\begin{abstract}
Abstrak: Sejauh ini teori psikologi (psikoanalisis) Lacan hanya digunakan sebagai pisau analisis, baik karya teks (sastra), pertunjukan, film maupun karya seni rupa. Berpijak dari hal tersebut, penulis menawarkan interprerstasi lain tentang aplikatif teori psikoanalisis Lacan sebagai dasar penciptaan skenario. Penelitian ini merupakan penelitian terapan berupa penciptaan skenario film pendek dengan pendekatan teori Lacan tentang the imaginary dan kelanjutan pada penciptaan film sebelumnya (sekuel kedua) dari Film Koper Gendis Mencari Jawab Menakar Tanya. Penciptaan skenario dengan pendekatan Lacan ini diharapkan menjadi alternatif baru pada ranah penciptaan skenario film.
\end{abstract}

Kata kunci: The Imaginary, Lacan, skenario film, Koper Gendis

\begin{abstract}
So far, Lacan's psychological theory (psychoanalysis) has only been used as a tool of analysis, whether it be text (literature), performances, films, or works of art. The author used Lacan's psychoanalytic theory as the basis for scenario creation. This report is applied research in the form of short film scenario creation with Lacan's theory approach of the imaginary and the continuation of the previous film creation (as a second sequel) from Film Koper Gendis Mencari Jawab Menakar Tanya. This scenario creation is expected to be a new alternative in film scenario creation.
\end{abstract}

Keywords: The Imaginary, Lacan, film scenario, Koper Gendis

\section{Pendahuluan}

Film bertema psikologi masih mendapatkan tempat di hati para penonton. Nama-nama besar semacam Hicthcock, Cristoper Nolan, Pedro Almodovar juga Jhonathan Demme identik dengan film-film psikologi / psikoanalisis. Sineas Indonesia seperti Joko Anwar maupun Mouly Surya cukup konsisten dengan film psikologisnya. Karya-karya film dengan tema psikologi bisa dibilang sebagai film yang cerdas karena memiliki alur dan logika yang rumit. Meskipun begitu karya-karya tersebut tetap tidak asing bagi kita, seperti Beautiful Mind, Pintu Terlarang (2009), Silent of The
Lamb, Black Swan (2010), Fight Club, Modus Anomaly (2012), Fiksi dan masih banyak lainnya.

Sejauh ini pendekatan psikoanalisis khususnya Lacan baru diaplikasikan dalam kajian- kajian film. Psikoanalisis Lacan sejauh ini baru digunakan sebagai pisau analisis pada berbagai film (lihat beberapa penelitian sebagai berikut: Abriantoro, 2018; Nurul \& Zamroni, 2018; Rohma, 2017; Sadjadi, 2018; Siregar, 2011; Zucker, 2012), selain tentu Lacan utamanya banyak digunakan untuk mengkaji karya teks (sastra) seperti novel (Manik, 2016; Sahara, 2019), puisi (Monika, 2020) dan juga 
pertunjukan. Mungkin baru seni rupa yang sudah menggunakannya sebagai dasar analisis maupun dasar penciptaan seperti yang dilakukan oleh Maftukha pada penciptaan gambar (Maftukha, 2018). Berpijak dari riset awal penulis tentang aplikasi teori Lacan khususnya pada media film. Penulis merasa perlu menempatkan teori psikoanalisis Lacan sebagai dasar penciptaan skenario (film). Sejauh ini penulis belum menemukan konsep psikoanalisis Lacan digunakan sebagai dasar penciptaan skenario (film) disertai dengan pertanggungjawaban akademik. Skenario film dipilih karena skenario merupakan bagian paling awal dan rancangan atau kerangka untuk membuat film (Wibowo, 2016). Skenario merupakan dasar dari sebuah film. Seno Gumira menjelaskan "bahwa dengan skenario yang bagus sutradara yang nanggung bisa membuat film yang lumayan. Namun dengan skenario yang buruk, bahkan seorang sutradara yang hebat sekalipun tidak mungkin membuat film yang bagus" (Ajidarma, 2000), hal ini membuktikan bahwa skenario merupakan faktor yang penting dalam membuat film.

Keberangkatan psikoanalisis diawali oleh Freud dengan konsep id, ego dan super ego. Prinsip dasar dari psikoanalisis adalah bahwa prilaku manusia merupakan hasil dari konflik antara kekuatan dorongan naluri (Id) bawah sadar dan pengendalian serta pertahanan yang dihadapkan oleh super ego dan ego (Damayanti, 2006 : 29). Hill menjelaskan bahwa dalam diri seseorang yang mempunyai jiwa yang sehat, ketiga sistem ini merupakan satu susunan yang bersatu dengan harmonis (C. S. Hill, 2017). Psikoanalisis terus mengalami perkembangan dari Freud (1856-1939), Jung (1875-1961), hingga Lacan (1901-1981). Psikoanalisis Lacan dipilih karena Lacan merupakan psikoanalisis yang paling penting dan berpengaruh semenjak Freud ( $P$. Hill, 2002). Pemikiran Lacan berpengaruh penting terhadap dunia akademik kontemporer, khususnya bagi kaum feminis, ahli teori film, dan kritikus kebudayaan (Damayanti, 2006 : 144). Berpijak dari psikoanalisa Freud, Lacan kemudian mengkaji ulang unsur-unsur teori Freud, kemudian muncul dengan istilah dan gagasan sendiri untuk menjelaskan berbagai fenomena kejiwaan. Lacan's psychoanalytic apparatus is different from Freud's in important ways that make his work on a text less of a violation in New Critical terms (Kaplan, 1990). Lacan menjelaskan subjek melalui tiga kategori (triad) yaitu The Real, The Symbolic dan The Imaginary (Ali, 2010). Fase the Imaginary menarik karena pada tahap ini ditandai dengan fase cermin (mirror stage). Fase cermin terjadi antara umur enam hingga delapan bulan, fase ini merupakan moment ketika kita pertama kali mengenal diri kita sendiri dalam cermin. Fase ini merupakan pintu masuk menuju tatanan subyektifitas yang disebut sebagai sifat imajiner (Storey, 2010).

Berpijak dari pemaparan perihal penerapan penggunaan teori Lacan, maka sangat perlu dilakukan aplikasi Teori Psikoanalisis Lacan sebagai ide dasar teori penciptaan skenario film. Selain memberi kontribusi pada ranah penciptaan film, penelitian ini juga memberikan wawasan dan wacana bagi perkembangan ilmu perfilman khususnya penulisan skenario.

Pada tahun 2018 penulis membuat film pendek berjudul Koper Gendis Mencari Jawab Menakar Tanya, yang idenya terinspirasi dari kotak pertanyaan, salah satu pelajaran khas di SD Eksperimental Mangunan yang didirikan oleh Romo Mangun (Wibowo, 2019), film ini bercerita tentang kehidupan Gendis, seorang anak SD yang harus melihat kekerasan di rumahnya. Meskipun dengan pendekatan neorealisme Italia, film ini sangat kental dengan nuansa psikologis. Penulis bermaksud meneruskan film tersebut dengan membuat sekuel-nya 
dengan membuat skenarionya dengan konsep psikoanalisis Lacan, The Imaginary.

\section{Landasan Teori}

Psikoanalis is Lacan

Lacan menjelaskan subyek melalui tiga kategori (Ali, 2010) The Real, The Symbolik dan The Imaginari. Yang real adalah dunia sebelum ditangkap oleh bahasa atau arena yang belum terbahasakan, wilayah gelap yang tidak diketahui oleh manusia. Lacan menggambarkan sebagai saat "kepenuhan" atau "keutuhan" yang hilang ketika kita masuk kedalam bahasa. Yang Real terjadi pada masa seorang anak berusia 0-6 bulan. Sang anak belum mampu membedakan dirinya dari orang tua dan dunia sekitarnya, yakni belum menyadari batas-batasnya.

Yang Imajiner (The Imaginary) ditandai dengan proses yang disebut "Tahapan Cermin" (Mirror Stage) tahap ini terjadi pada anak yan berusia 6-18 bulan. Menurut Lacan manusia dilahirkan secara prematur. Artinya mereka tidak dapat secara langsung mengkoordinasikan gerakan dan organ-organ tubuhnya hingga usia tetentu.

Tahap cermin mencakup dinamisme libidinal disebabkan oleh identifikasi si anak dengan "Aku Ideal" atau "Ego Ideal" tahap ini adalah tahap pengenalan awal dirinya sebagai "a $k u$ " sebelum kemudian masuk pada tahap bahasa.

Tatanan simbolik (The Symbolic) merupakan wilayah realitas yang telah diungkapkan melalui bahasa. Ia merupakan kerangka impersonal yang berlaku dalam masyarakat, sebuah arena di mana setiap orang mengabil tempat di dalamnya. Tahap ini terjadi pada seorang anak berusia 18 bulan sampai 4 tahun. Tatanan simbolik merupakan ranah makna sosial, logika dan diferensiasi yang diterima - di dalam dan melalui itu si anak mulai menampilkan keinginan dan karenanya membentuk sebuah subjek mausiawi.

\section{Metode}

Dalam mewujudkan karya film, terlebih dahulu penulis merujuk pada tahapan-tahapan penciptaan kreatif seperti yang dikemukakan oleh Graham Wallas (dalam Damayanti, 2006: 23- 24). Tahapantahapan tersebut yaitu (a) preparation (persiapan), (b) incubation (pengeraman), (c) ilumination (tahap ilham, inspirasi), (d) verification (tahap pembuktian atau pengujian).

\section{Tahap Preparation (Pe rsiapan)}

Tahap ini merupakan pengumpulan informasi atau data yang diperlukan untuk memecahkan suatu masalah. Dengan bekal bahan pengetahuan maupun pengalaman, individu menjajaki bermacam-macam kemungkinan penyelesaian masalah. Di sini belum ada arah yang pasti/tetap, akan tetapi alam pikirannya mengeksplorasi macammacam alternatif (Damayanti, 2006: 23).

Pada tahap ini penulis melakukan riset SD Mangunan dengan kasus-kasus Kotak Pertanyaan. Hal ini dilakukan untuk mendapatkan data sebanyak-banyaknya. Penulis juga melakukan riset pustaka tentang Psikoanalisis Lacan.

\section{Tahapan Incubation (inkubasi)}

Tahapan ini adalah tahap ketika indvidu seakan-akan melepaskan diri untuk sementara dari masalah tersebut, dalam arti ia tidak memikirkan masalah secara sadar, tetapi mengeraminya dalam alam pra sadar, tahap ini penting artinya dalam proses timbulnya inspirasi (Damayanti, 2006: 2324).

Setelah data dan informasi terkumpul, maka akan muncul banyak gagasan. Pada tahap ini bahan mentah kemudian diolah dan diendapkan. Penulis merangkum semua data dan mengakumulasi menjadi satu bagian. Penulis mulai memilah 
data-data mana yang relevan untuk dipakai dan menjadi gagasan atau inspirasi.

\section{Tahap Ilumination (Iluminasi)}

Tahapan ini adalah tahap timbulnya insight atau Aha-Erlebins, saat timbulnya inspirasi atau gagasan baru, beserta prosesproses psikologis yang mengawali dan mengikuti munculnya inspirasi/gagasan baru (Damayanti, 2006 : 24).

Jika tahap sebelumnya masih bersifat dan bertaraf mencari-cari dan mengendapkan, pada tahap ini semua menjadi jelas dan terang. Pada saat inilah seorang penulis akan merasakan katarsis, kelegaan dan kebahagiaan karena apa yang semua menjadi gagasan dan samar-samar akhirnya menjadi sesuatu yang nyata. Pada tahap ini penulis kemudian memanifestasikan data-data yang telah diendapkan sebelumnya.

Pada tahap ini penulis melakukan manifestasi ide-ide dan data yang sudah ada dengan melakukan proses penciptaan skenario dengan tahapan-tahapan sinopsis, basic strory, penokohan, seting, treatment, first draft.

\section{Tahap Verification (Pembuktian atau pengujian)}

Tahapan ini disebut juga tahapan evaluasi, ialah ketika ide atau kreasi baru tersebut harus diuji terhadap realitas. Pada bagian ini diperlukan pikiran kritis dan konvergen. Dengan perkataan lain, proses divergensi (pemikiran kreatif) harus diikuti oleh proses konvergensi (pemikiran kritis) (Damayanti, 2006 : 23- 24).

Tahap ini disebut juga tinjauan secara kritis, pada tahap ini penulis melakukan evaluasi terhadap karya ciptanya, apabila jika diperlukan penulis bisa melakukan modifikasi, revisi yang berguna untuk menyempurnakan karya. Pada tahap ini penulis melakukan evaluasi dan revisi terhadap skenario first draft. Skenario kemudian diberikan kepada beberapa orang yang sengaja dipilih seperti sutradara, aktor, pengkaji film yang bisa memberikan masukan sesuai dengan kompetensi mereka masing- masing untuk menyempurnakan skenario. Apabila masukan tersebut dirasa sesuai, masukan tersebut dapat digunakan untuk semakin memperkuat skenario film, sehingga hasilnya bisa sesuai dengan apa yang diharapkan, kemudian menjadikannya skenario final draft.

\section{Hasil dan Pembahasan}

Penciptaan karya skenario ini menghasilkan skenario film pendek dengan cerita sebagai berikut ini:

Endang memilih pergi dari rumah setelah ia tahu bahwa di perutnya ada janin hasil hubungannya dengan Supri, apalagi Supri tidak bertanggung jawab, pergi dan menghilang entah kemana. Keluarganya yang hidup di bawah garis kemiskinan sudah tidak lagi membuat ia betah di rumah, apalagi ayah dan ibunya sering cekcok dan bahkan Kekerasan Dalam Rumah Tangga (KDRT). Setelah menggelandang hidup di jalan, Endang depresi berat. Hingga akhirnya ia dipertemukan dengan Prasojo lelaki berkulit putih halus dan bertutur sapa halus. Petemuannya dengan Prasojo membuatnya menemukan kembali makna hidup dan mencintai anak yang ada di dalam kandungannya. Apalagi Prasojo yang anak bangsawan itu mau menerima dirinya apa adanya, bahkan mau menikahinya dan merawat anak dalam kandungan perutnya.

Endang bahagia diterima oleh keluarga Prasojo dengan baik. Endang ingin anaknya, Bambang, bisa melupakan masa lalunya dan hidup menjadi manusia baru dan status baru, sebagai bangsawan. Endang selalu memberi sugesti pada Bambang sejak kecil bahwa dia adalah anak keturunan bangsawan. Kata-kata "kowe iki sopo" selalu terngiang-ngiang di kepala Bambang. Hidup dengan tata cara bangsawan 
kemudian dijalani Bambang. Hingga Akhirnya ia bercermin dan tahu siapa dirinya, Bambang bimbang harus kembali menjadi dirinya atau menjadi manusia baru dengan status baru dan melupakan masa lalu tentang keluarga besarnya.

Sebagai film sekuel, pilihan menghadirkan kehidupan masa lalu Bambang menjadi sebuah suspense dan menjadi dasar sebagai penerapan teori Yang Imajiner (The Imaginary) yang dituangkan dalam kata-kata (bahasa) "kowe iki sopo", "Tahapan Cermin" (Mirror Stage) menjadi awal pencerminan pada tokoh Bambang. Hal ini akan terus terbawa pada tokoh Bambang pada film sebelumnya. Kata- kata ini menjadi ikon pada tokoh Bambang.

Tahap inilah yang nantinya akan berlanjut pada konsep psikoanalisis Lacan tahap berikutnya yaitu Tatanan simbolik (The Symbolic) di mana wilayah realitas yang telah diungkapkan melalui bahasa. Tatanan simbolik merupakan ranah makna sosial, logika dan diferensiasi yang diterima - didalam dan melalui itu si anak mulai menampilkan keinginan dan karenanya membentuk sebuah subjek mausiawi.



Gambar 01. Rumah Tampak Depan.

(Foto oleh Leo, 2018)

Seting menjadi salah satu hal penting dalam film, seting tidak hanya menjadi pelengkap saja. Seting bisa menjadi simbol dan makna dalam film, seting bisa menjadi penanda suatu era. Maka pemilihan seting perlu betul-betul dipertimbangkan. Seting dalam skenario adalah sebuah rumah tua. Gambar 01 merupakan referensi seting rumah yang ditawarkan dalam konsep skenario ini.

Dalam cerita skenario film ini terdapat 3 tokoh, yaitu Endang, Prasojo dan Bambang. Pendeskripsian tokoh yang meliputi dimensi fisiologis, sosiologis dan psikologis kemudian memvisualkannya dengan gambar. Tokoh adalah yang melahirkan peristiwa. Ditinjau dari keterlibatannya dalam keseluruhan cerita, tokoh dibedakan menjadi dua yaitu tokoh sentral atau tokoh utama dan tokoh priferal atau tokoh tambahan. Tokoh utama dapat ditentukan dengan tiga cara, yaitu (1) tokoh itu paling terlibat dengan makna dan tema, (2) tokoh itu paling banyak berhubungan dengan tokoh lain dan (3) tokoh yang paling banyak memerlukan waktu penceritaan.
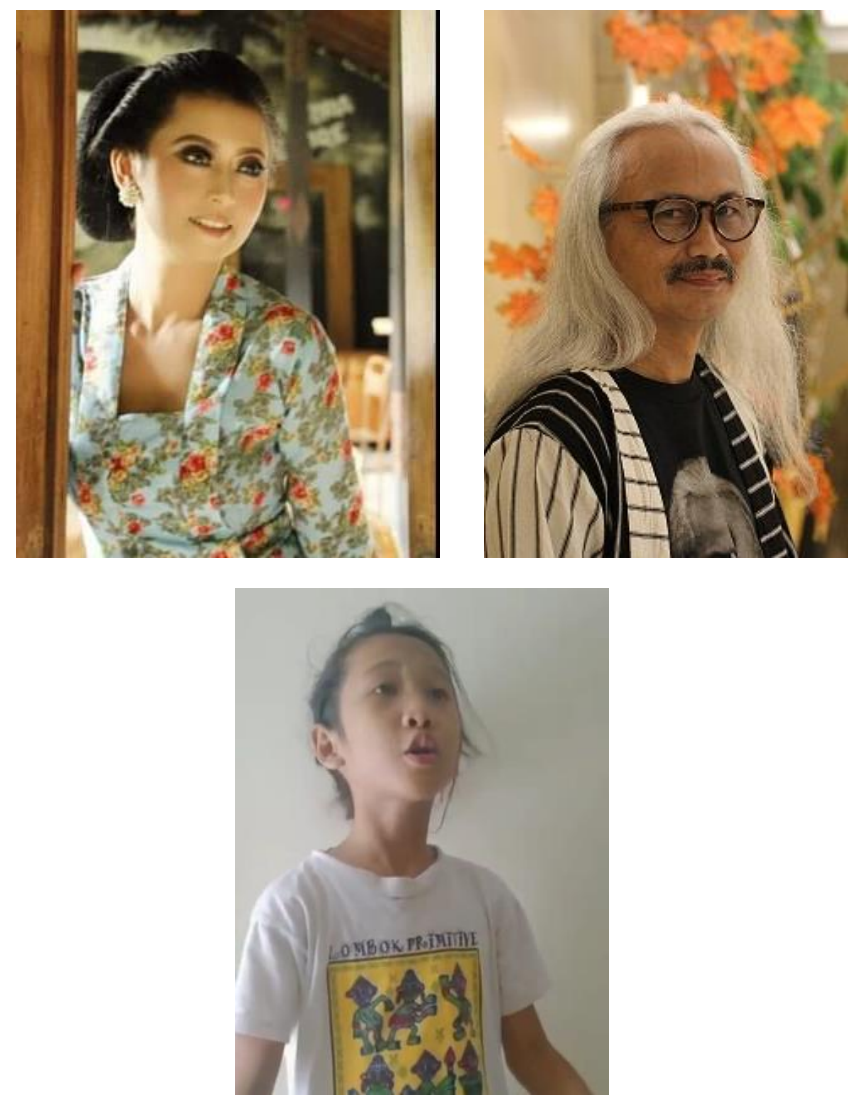

Gambar 02. Referensi Tokoh Endang, Prasojo dan Bambang

(Foto oleh Carol, 2018) 


\section{SIMPULAN}

Penelitian ini berupa penciptaan skenario film pendek yang merupakan sekuel kedua dari film Koper Gendis Mencari Jawab Menakar Tanya dengan konsep dengan pendekatan The Imaginary Lacan. Selain kuat secara psikoanalisis skenario film ini juga menghadirkan budaya Jawa. Penciptaan ini diharapkan memberikan wacana baru, sumbangan ilmu dalam perkembangan film Indonesia. Skenario film ini diharapkan memberikan kecemburuan positif kepada penulis skenario, pembuat film baik yang profesional maupun tidak untuk kemudian menciptakan karya film yang baru, sehingga ikut meramaikan perkembangan dunia perfilman Indonesia.

\section{Daftar Pustaka}

Abriantoro, W. Y. (2018). Fantasi Pada Popularitas Tokoh Dilan dan Milea dalam Film Dilan 1990 di Kalangan Mahasiswa UIN Sunan Ampel Surabaya (Vol. 2). Universitas Islam Negri Sunan Ampel Surabaya.

Ajidarma, S. G. (2000). Layar Kata :Menengok 20 Skenario Indonesia Pemenang Citra Festival Film Indonesia 1973- 1992. Yayasan Bentang Budaya.

Ali, M. (2010). Psikologi Film. Fakultas Film Dan Televisi Institut Kesenian Jakarta.

Damayanti, I. (2006). Psikologi Seni. Kiblat Buku Utama.

Hill, C. S. (2017). Naluri Kekuasaan Sigmund Freud. PT. Buku Seru.

Hill, P. (2002). Lacan untuk Pemula. Kanisius.

Kaplan, E. A. (1990). Psychoanalysis and Cinema. Routledge.

Maftukha, N. (2018). Psikoanalisis pada Visualisasi Karya Penderita Gangguan Kejiwaan di Unit Informasi Layanan
Sosial Meruya. Narada, 5(2), 153-174.

Manik, R. A. (2016). Hasrat Nano

Riantiarno dalam Cermin Cinta: Kajian

Psikoanalisis Lacanian. Jurnal Poetika, 4(2), 74. https://doi.org/10.22146/poetika.15492

Monika, L. (2020). Lacan dan Cermin Hasrat 'Aku' Lirik dalam Kumpulan Sajak Aku Ini Binatang Jalang Karya Chairil Anwar. Poetika, 8(1), 39. https://doi.org/10.22146/poetika.v8i1.5 6534

Nurul, B., \& Zamroni, M. (2018). Kajian Psikoanalisis Jacques Lacan dalam Film Opera Jawa (Analisis Fase the Real Tokoh Ludiro). Publikasi Budaya, 6(2), 110-114.

Rohma, N. N. (2017). Fantasi dalam Film Pohon Penghujan. Institut Seni Indonesia Surakarta.

Sadjadi, B. (2018). Language and ideology in film theory: The case study of the LAP model. Cogent Arts and Humanities, 5(1). https://doi.org/10.1080/23311983.2018. 1429078

Sahara, D. (2019). Hasrat Kurniawan dalam Novel Seperti Dendam, Rindu Harus Dibayar Tuntas (Kajian Psikoanalisis Jacques Lacan). Jurnal Salaka, 1(2), 216.

Siregar, H. A. A. (2011). Kontribusi Teori Interpretasi Psikoanalisis dan Hermeneutik Terhadap Proses Analisis/Pengkajian Film. Jurnal Sosioteknologi, 10(23), 1077-1092.

Storey, J. (2010). Pengantar Komperhensif Teori dan Metode Cultural Studies dan Kajian Budaya Pop. Jalasutra.

Wibowo, P. N. H. (2016). Novel Gadis Pantai Karya Pramoedya Ananta Toer Sebagai Dasar Penciptaan Skenario. Rekam: Jurnal Fotografi, Televisi, Dan Animasi. https://doi.org/10.24821/rekam.v11i1.1 291 
Wibowo, P. N. H. (2019). Penciptaan Film

Pendek Terinpirasi dari Kotak

Pertanyaan Pelajaran Khas Di SD

Eksperimental Mangunan. Tonil Jurnal

Kajian Sastra, Teater Dan Sinema:

Jurnal Kajian Sastra, Teater Dan

Sinema.

https://doi.org/10.24821/tnl.v16i2.3208
Zucker, C. (2012). CARROLL, Noel. Mystifying Movies: Fads and Fallacies in Contemporary Film Theory. New York: Columbia University Press, 1988. 262 p. Cinémas: Revue d'études Cinématographiques, 1(1-2), 154-162. https://doi.org/10.7202/1000998ar 